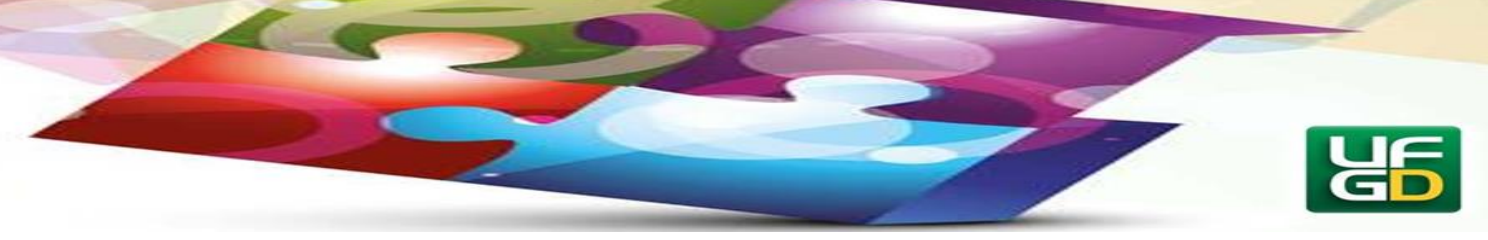

\title{
GAMIFICAÇÃO: UMA ESTRATÉGIA DIDÁTICA FUNDAMENTADA PELA PERSPECTIVA DA TEORIA DAS SITUAÇÕES DIDÁTICAS
}

\section{GAMIFICATION: A DIDACTIC STRATEGY BASED ON THE PERSPECTIVE OF THE THEORY OF DIDACTIC SITUATIONS}

\author{
Marcelo dos Santos GOMES ${ }^{1}$ \\ Maria José Ferreira da SILVA ${ }^{2}$
}

Resumo: o presente artigo trata de uma pesquisa qualitativa de abordagem bibliográfica, que tem como objetivo apresentar a gamificação como uma estratégia didática para o ensino de Matemática, buscando ressaltar sua definição e uma análise de suas vantagens e desvantagens a partir da perspectiva da Teoria das Situações Didáticas.

Palavras-chave: Gamificação. Teoria das Situações Didáticas. Estratégia Didática. Jogos.

Abstract: this article is a bibliographical research of qualitative approach, which purpose to show the gamification as a didatic strategy for the teaching of Math seeking to emphasize its definition and analyzing its advantage and disadvantage from the Theory of Didactical Situations persperctives.

Keywords: Gamification. Theory of Didactical Situations. Didactic Strategy. Games.

\section{Introdução}

$\mathrm{Na}$ atualidade, um dos grandes desafios em sala de aula é conseguir com que os alunos tenham interesse e motivação para participar das aulas, principalmente as de matemática. Por outro lado, sabemos que eles se envolvem profundamente em situações de jogos, provavelmente pelo ambiente que os jogos proporcionam. Nesse sentido, para McGonigal (2012), esses jogos inserem os jogadores em um ambiente que lhes propiciam uma relação de confiança e intensificação social, pois os jogadores podem jogar em grupos, de modo a concluírem um objetivo de forma coletiva e cooperativa.

\footnotetext{
${ }^{1}$ Mestre em Educação Matemática pela Pontífica Universidade Católica de São Paulo (PUC-SP). E-mail: marstosgomes@outlook.com

${ }^{2}$ Doutora em Educação Matemática pela PUC-SP. Professora no Programa de Estudos Pós-Graduados em Educação Matemática na mesma instituição. E-mail: zeze@pucsp.br
} 


\section{HORIZONTES - REVISTA DE EDUCAÇÃO}

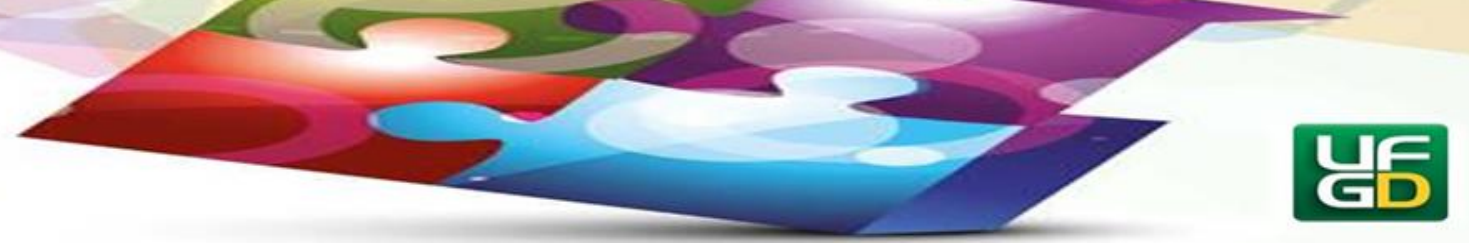

Convergindo com essa afirmação, Brousseau (1996) discorre que o ambiente propiciado por um jogo pode ser uma forma poderosa de representar a vida real, por serem excelentes modelos de situações reais, que permitem aos jogadores vivenciarem situações de ação, emoção e motivação que distinguem o jogo da realidade. Tais emoções e experiências que McGonigal (2012) afirma ser a sensação de fazer parte de algo maior que nós mesmos em que nossas ações transcendem nossas vidas individuais.

Assim, podemos destacar que para Gee (2005), existem novas maneiras de aprendizagem para uma geração de jovens e adultos que não veem os jogos apenas como um brinquedo, mas sim, como ferramenta de entretenimento frequente em suas vidas como atividades voluntárias levadas a sério e que podem promover a aprendizagem. Para Zille (2012), os jogos estabelecem ferramentas que auxiliam e configuram os pensamentos de seus jogadores, de modo a proporcionar ação e interatividade, além de ampliar e transformar a maneira de pensar e enxergar o mundo.

Dessa forma, acreditamos que uma dessas maneiras de aprendizagem pode ser pelo uso da Gamificação como estratégia, que possibilita ao aluno entrar em uma situação de ambiente de jogo, sem necessariamente ter um jogo específico, que lhe permite viver experiências que oportunizem a construção de novos conhecimentos ou novas habilidades. Sendo assim, nesse artigo apresentaremos o que é a gamificação, pela perspectiva de Karl Kapp, e buscaremos fundamentá-la pela Teoria das Situações Didáticas de Guy Brousseau, enquanto uma estratégica didática, observando suas potencialidades e restrições.

\section{Gamificação}

A gamificação é uma estratégia de incentivo, feedback e envolvimento que teve sua primeira aparição na área de marketing. Segundo Deterding et al. (2011), a gamificação é a utilização de elementos dos games ${ }^{3}$ em um sistema de não jogo, para melhorar o envolvimento e a experiência dos sujeitos em uma determinada tarefa. Em contrapartida, no âmbito educacional, Carolei (2014) a destaca como um processo de inserção da linguagem dos jogos em estratégias pedagógicas, isto é, utilizar os elementos de jogos que compõem a gamificação

\footnotetext{
${ }^{3}$ No presente artigo, utilizaremos as palavras “jogos" para representar qualquer tipo de jogo, enquanto utilizaremos "jogos digitais" e "games" como sinônimos.
} 


\section{MORIZONTES - REVISTA DE EDUCAÇÃO}

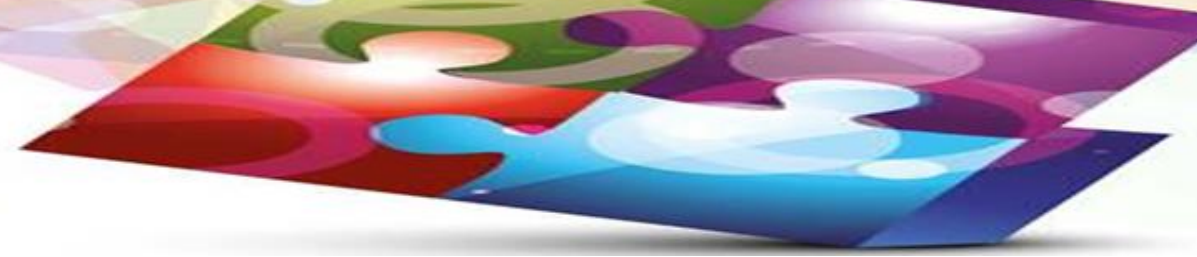

em atividades para promover o aprendizado em sala de aula. Para que essa estratégia seja possível é preciso compreender, de fato, o que é a gamificação e quais suas características.

Para Kapp (2012) o game é um sistema definido por regras para promover a interatividade, que produz feedbacks e uma saída quantificável, que permite ao sujeito sentirse fazendo parte dele. Assim, para o autor, a gamificação é o uso de mecânicas, estéticas e pensamentos dos games de modo a envolver pessoas, motivar a ação, solucionar problemas e promover a aprendizagem. De acordo com o autor, as Mecânicas são os elementos básicos que compõem qualquer jogo, como por exemplo, as regras, o sistema de feedback, a saída quantificável, os níveis de dificuldade, as recompensas, entre outros. A Estética é responsável pelas interfaces dos games, com cenários e gráficos agradáveis e harmônicos que influenciam o sujeito a interagir com o jogo. Já o Pensamento permite formular possíveis soluções para resolver problemas inseridos em um ambiente de jogo.

Para Gomes (2017), um ambiente gamificado deve promover aos jogadores, a partir da cooperação e competitividade saudável, a busca de soluções para problemas como um objetivo comum. Assim como Kapp (2012) discorre que a gamificação promove o envolvimento que permite captar a atenção do sujeito, ou de um grupo de indivíduos, para conduzi-los a participar de forma significativa no que é proposto, pois a proposta deve se encarregar de criar disposição, energia, propósito e significado ao comportamento e às ações dos jogadores.

A promoção de aprendizagem nesse tipo de ambiente, na perspectiva de Kapp (2012), tem características muito similares às adotadas pelos professores em sala de aula, como por exemplo, a distribuição de pontos, a existência de feedback e o encorajamento para a colaboração em atividades extracurriculares que constam nos planos pedagógicos. Por outro lado, seu diferencial é o modo como todas essas características estão relacionadas e são abordadas. Todavia, o autor alerta que nem todos esses elementos precisam estar inseridos em uma atividade gamificada, mas somente aquelas necessárias para que o objetivo final da atividade seja alcançado.

Kapp (2012) discorre que todos os elementos possuem sua importância e juntos formam uma excelente ferramenta para conquistar o sujeito, de modo que ele tenha dedicação e empenho em participar da atividade munida da gamificação. Acrescenta que ao utilizar a gamificação é preciso ter cautela e considerar o pensamento dos games para resolver problemas 


\section{HORIZONTES - REVISTA DE EDUCAÇÃO}

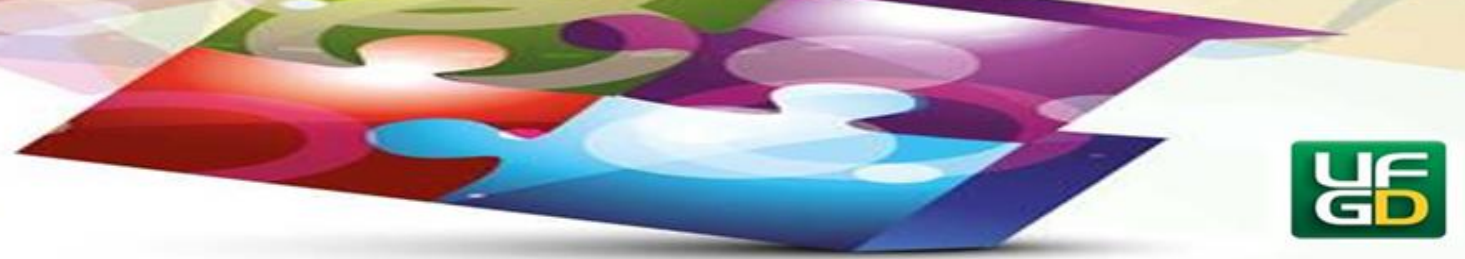

e proporcionar a aprendizagem usufruindo de todos os elementos dos games que forem apropriados.

Convergindo com essas afirmações, Landers et al. (2015) ressalta a importância de conhecer claramente os efeitos da gamificação antes de realizá-la. O papel fundamental que as motivações intrínsecas e extrínsecas que estão inseridas em uma atividade gamificada possuem. A esse respeito, Zichermann e Cunningham (2011) destacam que as motivações intrínsecas são aquelas que se originam dentro de nós e não se baseiam no mundo externo, podendo ser definidas como atividades em que os sujeitos se envolvem espontaneamente por puro estímulo, interesse e prazer. Em contrapartida, as motivações extrínsecas são aquelas externas ao indivíduo, ou seja, as recompensas emocionais.

No entanto, Gomes (2017) ressalta que é preciso tomar cuidado ao utilizar demasiadamente as motivações extrínsecas, pois este feito pode promover aos indivíduos um envolvimento superficial, que faz com que eles se importem apenas com as recompensas e não com o real objetivo da atividade. Como por exemplo, Khan Academy ${ }^{4}$ uma plataforma que está munida dos mecanismos de recompensa, com o objetivo de auxiliar os alunos em seus estudos, por meio da realização de exercícios de matemática, e como recompensa, recebem medalhas por conclusão das tarefas propostos.

Para Werbach e Hunter (2012), esse uso abusivo de recompensas para promover a motivação extrínseca recebe o nome de Pontificação ${ }^{5}$. Entretanto, essa plataforma enaltece apenas os acertos dos alunos desconsiderando seus erros. Sendo que no processo de aprendizagem é preciso levar o erro em consideração, como afirmam Macedo, Petty e Passos (1997), Grando (2000) e Gomes (2017) em que se permite o aluno analisar seu erro em uma situação problema, de modo que sua aprendizagem possa ocorra de forma significativa.

Visando promover uma melhor compreensão a respeito da gamificação, Kapp, Blair e Mesh (2014) as classificam em dois tipos: gamificação estrutural e gamificação de conteúdo (ou gamificação conceitual). Segundo os autores, a gamificação estrutural é a utilização de elementos dos jogos para incentivar, motivar e envolver os alunos a compreender um determinado conteúdo que não sofreu alterações, alterando apenas a forma como o conteúdo é apresentado para os alunos, geralmente, com a inserção de pontos, emblemas e níveis.

\footnotetext{
${ }^{4}$ Disponível em: <https://pt.khanacademy.org/>.

${ }^{5}$ É um neologismo do termo Pointsfication que tem origem da língua inglesa.
} 


\section{HORIZONTES - REVISTA DE EDUCAÇÃO}

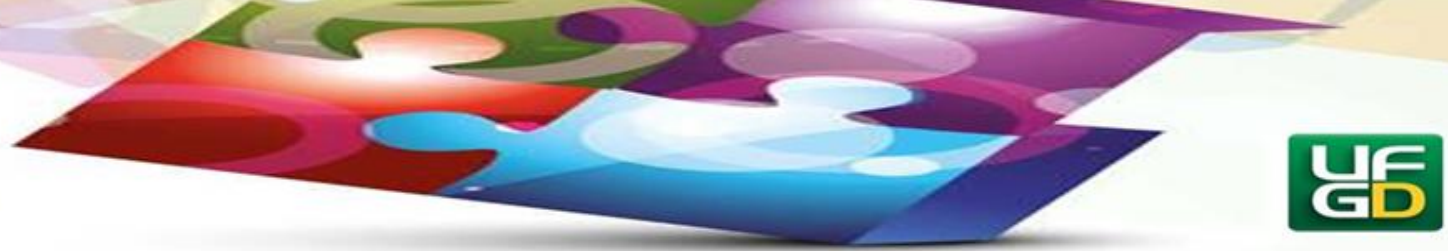

Em outras palavras, a gamificação estrutural usufrui das motivações extrínsecas, sendo possível também, adicionar elementos como história, personagens, entre outros, para criar um ambiente de jogo sem modificar o conteúdo a ser ensinado. Um exemplo deste tipo de gamificação pode ser encontrado no livro de McGonigal (2012), quando a autora descreve o projeto Quest to Learn ${ }^{6}$ que foi desenvolvido em uma escola pública na cidade de Nova York nos níveis equivalentes ao Ensino Fundamental II e Ensino Médio com o objetivo de transformar o ambiente escolar similar a um ambiente de jogo.

Embora o currículo tenha sido elaborado, como qualquer outro, para que os alunos aprendam matemática, história, geografia, arte, línguas estrangeiras, entre outras disciplinas em diversos horários ao longo do dia, seu diferencial está no modo como esses jovens aprendem, pois estão envolvidos em atividades que abordam conteúdos de todas as disciplinas em um formato de desafios.

Já a gamificação de conteúdo é a aplicação dos elementos de jogos para alterar um conteúdo e transformá-lo em um jogo, ou seja, cria-se um jogo para ensinar um determinado conteúdo, modificando sua estrutura, de modo que ele possa ser apresentado e desenvolvido enquanto o aluno joga. Um exemplo deste tipo de gamificação pode ser encontrado na tese de Tonéis (2015), em que o autor criou um jogo de RPG (Wind Phoenix) para proporcionar situações que auxiliem seus alunos no aprimoramento e desenvolvimento de habilidade matemáticas ao jogarem, como por exemplo: a superação da resolução dos problemas por tentativa e erro, permitindo-os observar que criar estratégias e formular planos é muito mais eficaz, o aprimoramento da atenção e da concentração, contextualização de questões de porcentagem dentro do jogo, a noção de proporção em termos fracionários, entre outros.

Assim, destacamos que a gamificação é uma estratégia didática que pode promover a aprendizagem e, como tal, apresentamos as suas vantagens que englobam a utilização de ferramentas associada à linguagem dos jogos, que pode potencializar a aprendizagem. Entre as desvantagens, nos deparamos com o uso abusivo das motivações extrínsecas que podem atrapalhar o desenvolvimento do aluno no processo de aprendizagem.

No entanto, precisamos ter conhecimento do seu uso, como frisa Gomes (2017, p. 57) “a utilização da gamificação está muito associada ao uso dos jogos no ensino e aprendizagem,

\footnotetext{
${ }^{6}$ Disponível em: <http://www.q2l.org/>.
} 


\section{HORIZONTES - REVISTA DE EDUCACÃ̃O}

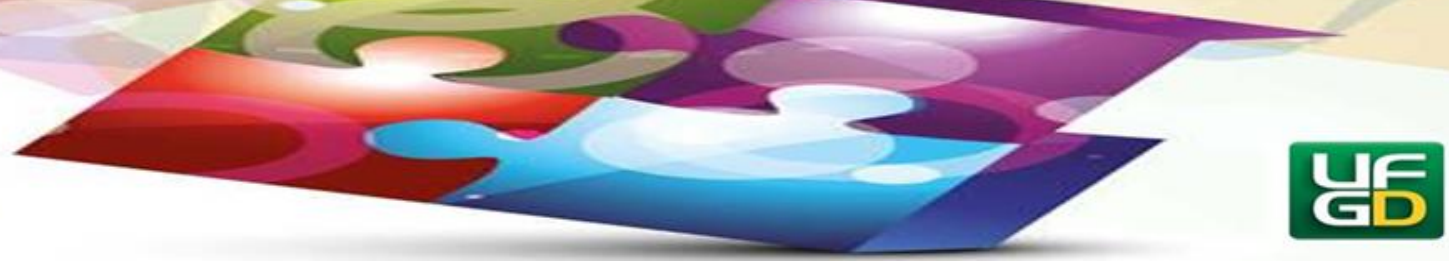

porém, deixamos explícito que a gamificação é muito mais que apenas a prática dos jogos e jogos digitais no âmbito escolar”. Portanto, utilizar gamificação não é apenas inserir jogos em sala de aula e, sim, utilizar de todo benefício e envolvimento que o ambiente de jogo propicia aos alunos no seu processo de aprendizagem.

Desse modo, acreditamos que ao migrar para o ambiente da educação, é necessário analisar e estudar outros fatores com o objetivo de promover aprendizagem, como por exemplo, o papel do aluno e do professor no processo de ensino e aprendizagem. Sendo assim, analisamos a gamificação embasada na Teoria das Situações didáticas de Guy Brousseau.

\section{Gamificação embasada na TSD}

De acordo com Gomes (2017), a Teoria das Situações Didáticas é uma teoria da área de Educação Matemática que pode ser utilizada para melhor compreensão da gamificação como uma estratégia de ensino.

Para Almouloud (2007), Brousseau desenvolveu a Teoria das Situações Didáticas visando modelar o ensino e a aprendizagem de conceitos matemáticos entendendo que o processo de aprendizagem ocorre por meio de uma sequência de situações que podem ser reproduzidas e provoquem modificações nos conjuntos de comportamentos dos alunos. Para Brousseau (1996), esta situação deve promover um envolvimento voluntário do aluno, de maneira que o leve a agir, falar, refletir e evoluir de forma autônoma e o conduzir a adquirir um novo conhecimento. O que converge com a afirmação de Freire (1996), de que ensinar não é transferência de conhecimento e, sim, criar possibilidades para que o aluno possa construir de forma atuante a aquisição de um novo saber.

Segundo Almouloud (2007), Brousseau modeliza as situações adidáticas em termos de um jogo a partir de uma situação que promova a aprendizagem do aluno, de modo atuante, elaborando estratégias para iniciar o jogo, compreendendo o problema proposto e suas regras. Em resumo, a modelização das situações didáticas (das quais fazem parte as situações adidáticas) é constituída por quatro dialéticas: dialética de ação, dialética de formulação, dialética de validação e dialética de institucionalização.

De acordo com Almouloud (2007), a dialética da ação está baseada em colocar o aluno em uma situação de ação, ou seja, esse é o momento em que o aluno irá explorar o jogo, 


\section{HORIZONTES - REVISTA DE EDUCAÇÃO}

conhecer as regras, buscando solucionar o problema ao interagir com o ambiente de jogo. A dialética de formulação é a fase em que o aluno troca informações com um ou mais colegas, com o objetivo de explicitar sua solução por meio da língua materna e de matemática, seja escrita ou oral, de modo a promover debates em busca de validar suas conjecturas.

O autor prossegue destacando que a dialética da validação ocorre no momento em que o aluno valida sua solução para o problema proposto, validando as conjecturas formuladas nas fases de ação e de formulação. Por serem dialéticas, esses momentos não acontecem isoladamente, mas imbricados durante toda a ação do aluno. E por fim, o autor destaca a dialética de institucionalização como a fase em que o professor, de forma explícita, valida o novo conhecimento matemático envolvido na situação proposta, ou seja, oficializa o novo saber para o aluno, de modo que o novo conhecimento incorpore os esquemas mentais do aluno.

Dessa forma, Gomes (2017) afirma que como a gamificação é uma estratégia de ensino que sugere a utilização de elementos encontrados nos jogos e jogos digitais para engajar e promover o envolvimento dos alunos em situações de aprendizagem, então ela pode ser explicada pela TSD, pois nesta o professor precisa elaborar uma situação para o aluno sair de sua zona de conforto e ser atuante durante sua aprendizagem, ou seja, agir, formular e validar. Assim, uma situação gamificada pode ser entendida como uma situação didática na perspectiva de Brousseau.

Gomes (2017) afirma que ao destacar os objetivos, as regras e o tempo na gamificação os objetivos são fundamentais para guiar o aluno a tomar para si a solução da tarefa. Para Brousseau (1996), é no ato de jogar que o aluno visualiza seu objetivo e, consequentemente, cria estratégias para concluí-lo.

Por outro lado, as regras envolvidas em uma atividade em sala de aula fazem parte do contrato didático. Segundo Almouloud (2007), essa noção foi introduzida para analisar as relações que são estabelecidas entre o professor e seus alunos e sua influência sobre a aprendizagem de Matemática. Esse contrato é, de acordo com o autor, o conjunto de comportamentos do professor, esperado pelos alunos e, ao mesmo tempo, o conjunto de comportamentos dos alunos, esperado pelo professor. Acrescenta que o funcionamento desse contrato depende, em parte, das escolhas pedagógicas do professor e, portanto, podemos dizer que a escolha de uma situação gamificada faria parte de um novo contrato didático adotado pelo professor. 


\section{HORIZONTES - REVISTA DE EDUCAÇÃO}

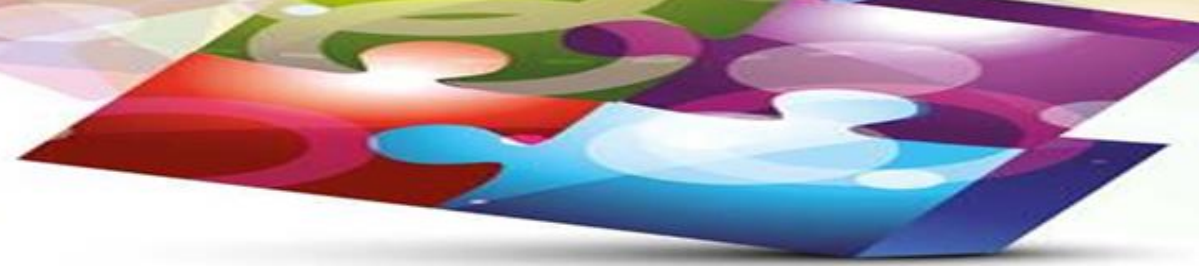

De acordo com Fardo (2013), a Gamificação é uma estratégia que aplica elementos, geralmente, encontrados nos games, para engajar e promover o envolvimento dos sujeitos em situações direcionadas ao ensino e à aprendizagem e, também, qualquer ambiente que propicie a aprendizagem.

Kapp (2012) descreve alguns desses elementos como: objetivo, regras, tempo, conflito, competição e cooperação, feedback, nível de dificuldade, abstração da realidade e criação de história. Para o autor o tempo é um fator crítico para o sucesso, pois caso não seja distribuído adequadamente poderá comprometer o desempenho do jogador. Para Gomes (2017), essa questão do tempo também é tratada na TSD, quando orienta que o professor deve considerar o tempo necessário para os alunos desenvolverem a atividade e assim não provocar rupturas no contrato didático.

Já a questão do conflito, que segundo Kapp (2012) está relacionado à existência de um desafio, podemos justifica-lo na TSD pelo meio antagonista proposto por Brousseau, pois é nele que se desestabiliza o sistema didático, provocando novos problemas ou novas situações. $\mathrm{Na}$ construção de uma efetiva problematização é necessário ocorrer um desafio que motive o aluno a solucionar o problema proposto e essa problematização, de acordo com Carolei (2014) é que conduz o aluno a um desequilíbrio cognitivo que poderá ser uma excelente ferramenta para envolver o sujeito na tarefa.

O elemento competição, estipulado por Kapp (2012), é aquele em que o sujeito aperfeiçoa seu desempenho para superar algum adversário ou a si mesmo, sendo responsável por propiciar ao sujeito a ampliação da atenção e o aprimoramento de seu desempenho no jogo. Nesse sentido, Grando (2000) ressalta que a competição promove dinamismo, interesse e envolvimento espontâneo dos alunos, de modo a propiciar uma autoavaliação de seu desempenho e suas limitações.

A cooperação, segundo Kapp (2012), significa trabalhar em conjunto e alcançar um objetivo em comum para todos os sujeitos envolvidos na atividade, ou seja, é o ato de trabalhar em conjunto, com outras pessoas em torno de um único objetivo. Esse elemento pode ser justificado na TSD na fase de formulação, quando, de acordo com Almouloud (2007) o sujeito precisa interagir com os demais para confrontar seus raciocínios e assim chegarem, de modo cooperativo, à solução da atividade. 


\section{HORIZONTES - REVISTA DE EDUCAÇÃO}

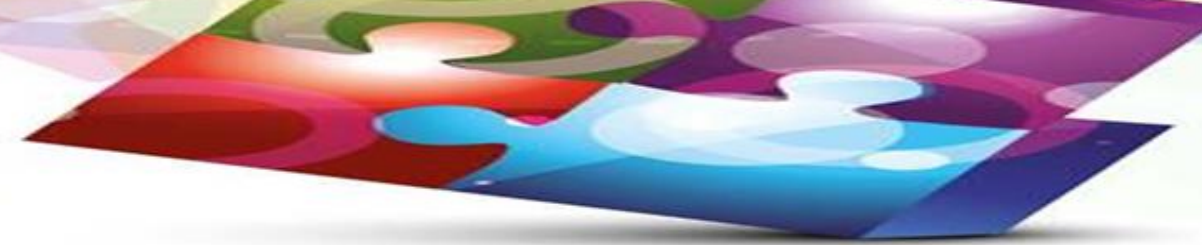

Ao abordar o elemento feedbacks, Kapp, Blair e Mesch (2014) afirmam que em um ambiente de jogo, eles proporcionam aos jogadores informações a respeito de seu desempenho no jogo e, caso seja pertinente, a mudança de seu comportamento. De acordo com Brousseau (1996), o professor é quem formula o jogo e, consequentemente, estabelece as regras de base que irão compor o contrato didático e, assim, considerar os momentos apropriados para realizar as intervenções necessárias, sem tirar a autonomia do aluno. $\mathrm{O}$ feedback dado pelo professor para a atividade do aluno precisa ser realizado nos momentos apropriados para que não prejudique seu desempenho. Por outro lado, de acordo com Gomes (2017, p. 85) "encontraremos os feedbacks nos momentos de devolução, em que o professor no papel de observador poderá fazer as intervenções que julgar apropriadas" procurando sempre devolver a solução da atividade para o aluno.

E por fim, ao destacar os elementos nível de dificuldade, abstração da realidade e criação de história.

Kapp (2012) aborda o elemento nível de dificuldade de três formas diferentes em um ambiente de jogo: estrutura de nível ou missões em que a dificuldade aumenta conforme o sujeito avança nas fases ou missões; nível escolhido no início do jogo, por exemplo: iniciante, fácil, médio, difícil, profissional, entre outras nomenclaturas e, o último tipo de nível é aquele que depende da experiência do jogador, pois na medida em que os sujeitos aprimoram suas habilidades, proporcionalmente, o nível de dificuldade aumenta.

Gomes (2017) discorre, na perspectiva da TSD, que o nível de dificuldade precisa ocorrer de modo proporcional ao desempenho e habilidades dos jogadores, caso contrário, a atividade poderá se tornar desestimulante ou maçante, seja por ser fácil demais ou muito difícil.

O elemento abstração de realidade e a criação de história estão interligados. Para Kapp, Blair e Mesch (2014) a utilização da história propicia ao indivíduo abstrair-se da realidade, o que poderá ser benéfico para criar um ambiente em que o novo conhecimento se tornará essencial, em virtude de todo o contexto histórico. Tais elementos podem ser justificados diretamente por Brousseau (1996) quando afirma que o jogo se assemelha à vida real, porque exige do jogador uma situação de ação, emoção, motivação, divergindo apenas, no quesito controle de situações, porque na realidade não temos controle sobre elas.

Sendo assim, Gomes (2017) evidencia que o termo criação de história esteja relacionado com a existência de uma coerência e coesão no contexto proposto pela atividade, seja de fato 


\section{HORIZONTES - REVISTA DE EDUCACÃ̃O}

e-ISSN: 2318-1540

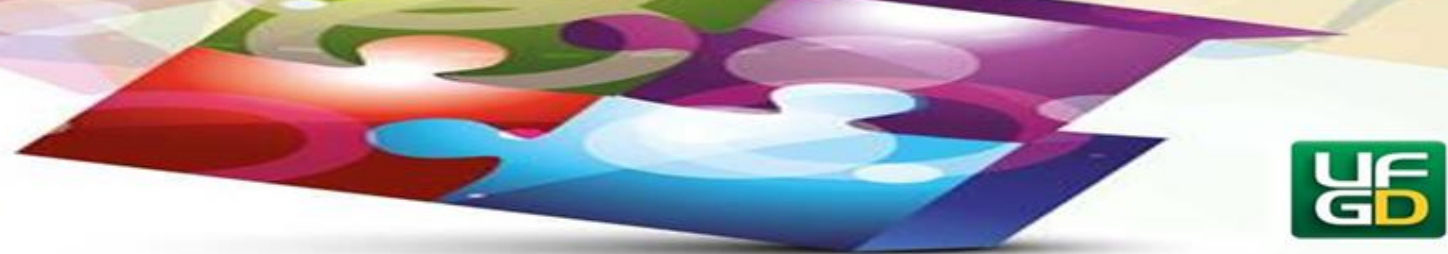

criar uma história, ou apenas dar um sentido ao problema proposto, de modo que o aluno depare-se com o problema e busque solucioná-lo.

O autor ressalta que os elementos da gamificação: objetivo, regras, tempo, conflito cognitivo, cooperação, feedbacks, níveis de dificuldade, entre outros, podem ser entendidos por meio das dialéticas de ação, de formulação e de validação da Teoria das Situações Didáticas. O autor afirma também, a exímia importância de que ambas propõem um ambiente de jogo para promover a aprendizagem. Porém,

[...] quando nos referimos a institucionalização, enaltecemos que o professor deve fazer uma intervenção no sentido de relacionar os conhecimentos construídos pelos alunos a um saber instituído que é o objetivo primordial da intervenção didática, proposta pelo professor.

Assim, discorrer a respeito do ensino e da aprendizagem de um conhecimento de um determinado saber científico, exige que o professor relacione os novos conhecimentos a um saber matemático descontextualizado para que seja assimilado e incorporado aos esquemas mentais dos alunos (GOMES, 2017, p. 85).

Dessa forma, segundo a perspectiva de Gomes (2017), podemos observar que a gamificação não apresenta, claramente, em sua estrutura o momento da institucionalização.

\section{Considerações Finais}

O presente artigo teve como objetivo destacar a gamificação como uma estratégia didática a partir de suas características e potencialidades, visando apresentá-la sob embasamento da Teoria das Situações Didáticas, como propõe Gomes (2017), que converge para as afirmações de Landers et al. (2015) de que é de suma importância que ocorra associações entre teorias de aprendizagem com a gamificação para enriquecimento de seu estudo.

A utilização da gamificação como estratégia de ensino exige conhecimentos das ferramentas dos games que serão utilizadas, bem como clareza de suas vantagens e desvantagens. Caso contrário, equívocos podem acontecer, como por exemplo, a supervalorização de recompensas extrínsecas que pode deixar o saber a ser assimilado em segundo plano. Além disso, a estratégia de ensino por gamificação transcende a ideia de apenas inserirem jogos ou jogos digitais, porque seu uso está associado ao ambiente de jogo, assim 


\section{HORIZONTES - REVISTA DE EDUCAÇÃO}

e-ISSN: 2318-1540

como propõe a TSD, embora não esteja ligada necessariamente, à utilização obrigatória de um jogo.

Adotamos para este trabalho os elementos da gamificação definidos por Kapp (2012): objetivo, regras, tempo, conflitos cognitivos, competição, feedbacks, entre outros. O que nos possibilitou observar que um ambiente para o ensino composto por esses elementos podem permitir a utilização de situações adidáticas no sentido da TSD para que os alunos sejam atuantes ao transitar pelas fases de ação, formulação e validação como prevê tal teoria.

Portanto, como a teoria justifica a estratégia didática e, no momento, de elaborar uma aula munida de gamificação norteada pela TSD os professores devem compreender quais as melhores ferramentas da gamificação o auxiliarão a alcançar seus objetivos de ensino e de aprendizagem de um determinado conteúdo ou aprimorar habilidades matemáticas.

Em outras palavras, a TSD acrescenta a necessidade do momento de institucionalização a essa estratégia de ensino, pois sem ela o conhecimento construído pelos alunos não é formalizado e associado a um saber. Ao inserir a fase da institucionalização, após o momento em que o aluno valida suas hipóteses durante a situação o professor busca agregar o novo saber aos esquemas cognitivos do aluno.

De acordo com Brousseau (1996), cabe o professor elaborar situações que promovam aos alunos a oportunidade de mobilizar seus conhecimentos, de debater, de argumentar e de refletir a respeito de suas escolhas para resolver a situação proposta pelo professor. Em contrapartida, é função dos alunos vivenciar as situações que os permitam agir, provar, construir modelos linguísticos, conceituais e teóricos com autonomia e discernimento de suas escolhas e se estas são, ou não, as mais pertinentes. Sendo assim, a Teoria das Situações Didáticas auxilia para uma melhor compreensão da gamificação como estratégia de ensino de modo a ampliar a visão de suas potencialidades para o ensino e a aprendizagem da matemática.

\section{Referências}

ALMOULOUD, S. A. Educação Matemática: Fundamentos da didática da Matemática. Paraná: Editora, da UF de Paraná, 2007.

BROUSSEAU, G. Fundamentos e métodos da didática da matemática. In BRUN JEAN (Org.) Didáctica das matemáticas. Tradução: Maria José Figueiredo. Lisboa: Instituto Piaget, 1996. p. $35-113$. 


\section{HORIZONTES - REVISTA DE EDUCAÇÃO}

e-ISSN: 2318-1540

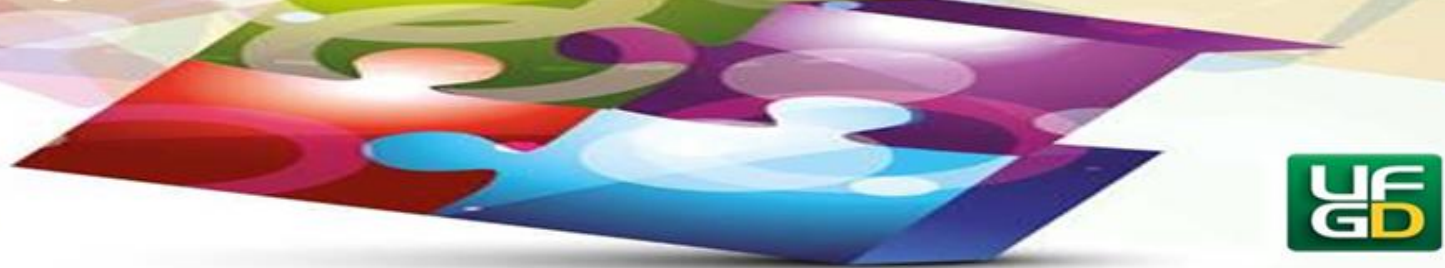

CAROLEI, P. Games Pervasivos como proposta de potencialização da Comunicação Científica. In: XXXVII Congresso Brasileiro da Ciência da Comunicação - Foz do Iguaçu 2 a 5/09 de 2014 no GT GP Comunicação, Ciência, Meio Ambiente e Sociedade, 2014.

DETERDING, S., SICART, M., NACKE, L. E., O'HARA, K. and DIXON, D. Gamification: Using Game Design Elements in Non-Gaming Contexts. In: Proc. Of the 2011 Annual Conference on Human factor in Computing Systems - CHI 2011, Vancouver, Canada, 2011.

FARDO, M. L. A Gamificação como estratégia pedagógica: Estudos de elementos dos games aplicados em processos de ensino e aprendizagem. 2013. Dissertação (Mestrado em Educação) - Universidades de Caxias do Sul, Caxias do Sul, 2013.

FREIRE, PAULO. Pedagogia da autonomia: saberes necessários à prática educativa. São Paulo: Paz e Terra, 1996.

GEE, J. P. Video Game and the future of learning. WCER Working Paper No. 2005 - 4.

GOMES, M. S. Gamificação e Educação Matemática: uma reflexão pela óptica da Teoria das Situações Didáticas. 2017. 96p. Dissertação (Mestrado em Educação Matemática), Pontifícia Universidade Católica de São Paulo, Faculdade de Ciências Exatas e Tecnologia, São Paulo, SP, 2017.

GRANDO, R. C. O conhecimento matemático e o uso de jogos na sala de aula. 2000. Tese (Doutorado em Educação) - Faculdade de Educação, UNICAMP, Campinas, 2000.

KAPP, K. M. The Gamification of learning and Instruction: Game-based Methods and Strategies of Training and Education. Pfeiffer, 2012.

KAPP, K. M., BLAIR, L., MESCH, R. The Gamification of Learning and Instruction Fieldbook: Ideas into Practice. Wiley, 2014.

LANDERS, R. N., BAUER, K. N., CALLAN, R. C., ARMSTRONG, M. B. Psychological Theory and the Gamification of Learning. In: T. Reiner, L. C. Wood (eds). Gamification in Education and Business. Springer, 2015. p. 165 - 182.

MACEDO, L., PETTY, A. L. S.; PASSOS, N. C. 4 Cores, Senhas e Dominó. São Paulo: Casa do Psicólogo, 1997.

MCGONIGAL, J. A. Realidade em jogo: por que os jogos nos tornam melhores e como eles podem mudar o mundo. Tradução de Eduardo Rieche. Rio de Janeiro: Best Seller LTDA, 2012.

TONÉIS, C. N. A Experiência Matemática no Universo dos Jogos Digitais: O processo do jogar e o raciocínio lógico e matemático. 2015. Tese (Doutorado em Educação Matemática) Universidade Anhanguera de São Paulo, São Paulo, 2015. 


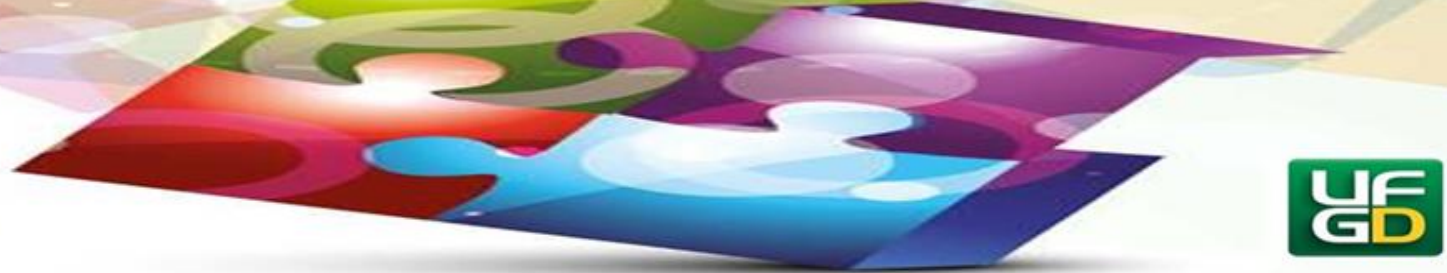

WERBACH, K., HUNTER, D. For The Win: How Game Thinking Can Revolutionize Your Business. Filadélfia, Pensilvânia: Wharton Digital Press, 2012.

ZICHERMANN, G., CUNNINGHAM, C. Gamification by Design. Implementing Game Mechanics. in Web and Mobile Apps. Canada: O’Reily Media, 2011.

ZILLE, J. A. B. A intensificação do agenciamento nos games: do jogador ao jogador-criador. 2012. Tese (Doutorado em Comunicação e Semiótica) - Pontifícia Universidade Católica de São Paulo, São Paulo, 2012.

Enviado:05/07/2018

Aceito: 04/09/2018 